\title{
Development of Absorbents with High Contact Area for Applications in Desiccant Coated Heat Exchanger
}

\author{
Yunxi Li \\ Hisense Air Conditioner R\&D Centre \\ Hisense (Shandong) Air Conditioner Co. \\ Ltd. \\ Qingdao, China \\ liyunxi@hisense.com
}

\author{
Benwei Li \\ Hisense Air Conditioner R\&D Centre \\ Hisense (Shandong) Air Conditioner Co. \\ Ltd. \\ Qingdao, China \\ libenwei@hisense.com
}

\author{
Zhigang Wang \\ Hisense Air Conditioner R\&D Centre \\ Hisense (Shandong) Air Conditioner Co. \\ Ltd. \\ Qingdao, China \\ wangzhiganghh@hisense.com
}

\begin{abstract}
Desiccant coated heat exchanger (DCHE) is developed from the combination of desiccant absorbents and the conventional fin-tube heat exchanger. The performance of the DCHE is mainly due to the adsorption properties of the coated absorbents. Therefore, to improve the DCHE performance, we fabricated porous ion exchange resin (IER) particles which have highly increased contact areas to be used as the DCHE absorbents. The water uptake and adsorption ratio of the porous and non-porous absorbents were both measured and compared against each other. The results showed that the absorbents with porous structure possessed higher water capacity and adsorption rate than that of the nonporous IER.
\end{abstract}

Keywords: air-conditioner; exchanger; desiccant; porous; ion exchange resin

\section{INTRODUCTION}

Generally, the dehumidification and humidification are achieved via refrigerating to condense the moist air below the dew point or heating the liquid water above the vapor temperature. Both directions of the humidity control caused plenty of energy waste, which decreased the coefficient of performance (COP) as well ${ }^{[1-7]}$. Recently, to control the indoor humidity and improve the COP of the conventional airconditioning system, researches on adsorption refrigeration technology has increased due to many advantages such as utilizing solar and geothermal energies and wastes heat ${ }^{[6-12]}$. The desiccant coated fin-tube heat exchanger a kind of the DCHEs, developed from the classic fin-tube heat exchanger which is widely used in nowadays air-conditioning system [1420].

Absorbents such as active carbons, silica gel, zeolites or ion exchange resins are the key component of the desiccant coated fin-tube heat exchanger ${ }^{[2,8,11,13]}$. Great efforts have been dedicated to investigating the performance of these materials. For example, silica gel has been both analytically and experimentally studied ${ }^{[11-13]}$. Computer simulation was also applied to optimize the performance of the adsorption refrigeration ${ }^{[14-15]}$.

Compared to those inorganic porous materials, IER can directly attach to the fin surfaces instead of mixing with epoxy resin, which avoids the decreasing of the contact area of the absorbents. However, the IER swells while absorbing water and shrinks after evaporation. The frequent dimensional change of the resin caused the serious decline in durability. Besides, the adsorption properties are

In this work, we propose IER with aromatic chain structures to provide high thermal and mechanical stabilities, which improves the longevity of the absorbents. The aromatic IER was also fabricated with porous structures to increase contact surface areas. The test results showed improved humidity adsorption rate and capacity due to the porous surfaces.

\section{EXPERIMENTAL}

$A$. Sythesis of IER

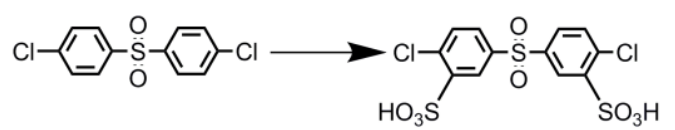

(a)

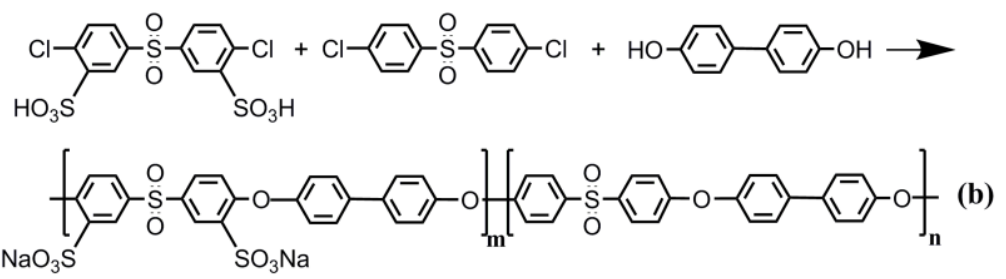




\section{Scheme 1. Preparation scheme of the sulphonated poly ether sulfone ion exchange resin (SPESIER).}

$B$.

\section{SPESIER}

Synthesis of the

The ion exchange resin was synthesized via two major steps as shown in Scheme 1. First, sulphonated bis (4-chlorophenyl) sulphone was obtained via a typical sulphonating procedure utilizing fuming sulfuric acid and bis (4-chlorophenyl) sulphone ${ }^{[21]}$. Then the sulphonated bis (4-chlorophenyl) sulphone was added into a three-necked, round-bottomed flask with $\mathrm{K}_{2} \mathrm{CO}_{3}$, biphenol and DMSO (solvent). The SPESIRE was polymerized via aromatic nucleophilic substitution polycondensation. The resulting polymer was washed with DI water and ethanol after polymerization.

C. porous absorbents particles.

Prepareation of

The size of the common used absorbents particles are usually in the range of $60 \sim 100 \mu \mathrm{m}$. Therefore, to develop the absorbents with porous surfaces, the pore size should be much smaller than that of the particle.

In this work, the porous structure was fabricated by the solution casting method. First, the SPESIER was dissolved into NMP with the solid content of $10 \%$ and stirring for $12 \mathrm{~h}$ at room temperature to get a homogeneous solution. Secondly, 1Ethyl-3-methlimidazolium tetrafluoroborate $\left(\mathrm{EMMBF}_{4}\right)$ was separately added into the solution at concentrations of $50 \mathrm{wt} \%$ of the SPESIER. The mixtures were then stirred for another $12 \mathrm{~h}$ to ensure uniform dispersion. The casting solution was filtered before pouring onto a flat glass substrate. The glass plates with casting solution on top were first held in the oven at $60^{\circ} \mathrm{C}$ for $12 \mathrm{~h}$ and then $80^{\circ} \mathrm{C}$ in vacuum for another $24 \mathrm{~h}$ to remove solvents. The dried polymers were then removed from the glass plate and boiled in methanol until constant weight to remove the $\mathrm{EMMBF}_{4}$ and residuals. The porous polymers were powdered into small particles and the pore structure was observed under SEM.

$D$.

Water uptake

Water uptake was measured after completely drying of the samples at $120^{\circ} \mathrm{C}$ in vacuum. Then their weights $\left(\mathrm{W}_{\text {dry }}\right)$ were recorded before immersing into DI water. Tests were carried out at different temperatures $\left(20^{\circ} \mathrm{C}, 40{ }^{\circ} \mathrm{C}, 60^{\circ} \mathrm{C}, 80{ }^{\circ} \mathrm{C}\right.$ and $\left.100{ }^{\circ} \mathrm{C}\right)$. The $\mathrm{W}_{\text {wet }}$ were measured after $10 \mathrm{mins}$ at each temperature. The water uptake of these membranes was calculated and compared as percentages by the following equation:

Water uptake $(\mathrm{wt} \%)=\left(\mathrm{W}_{\text {wet }}-\mathrm{W}_{\text {dry }}\right) / \mathrm{W}_{\mathrm{dry}} \times 100$

E.

Adsorption rate

The adsorption rate of the porous IER particles was measured and compared against the non-porous absorbents. The absorbent powder was first dried in the oven at the temperature of $120{ }^{\circ} \mathrm{C}$ until constant weight which was recorded as $\mathrm{W}_{\text {dry }}$. Then the absorbents were placed in a cube with the salt bath of $\mathrm{KCl}$ to create a constant relative humidity (RH) atmosphere. The weight change of these absorbents was continuously measured every 100 seconds.

The adsorption ratio was evaluated by the following equation:

Adsorption ratio $(\mathrm{wt} \%)=\left(\mathrm{W}_{\text {wet }}-\mathrm{W}_{\text {dry }}\right) / \mathrm{W}_{\mathrm{dry}} \times 100$

\section{RESULTS AND DISCUSSION}

A.

\section{Morphology}

$\mathrm{EMMBF}_{4}$ was used as the pore-forming agent due to its extraordinary compatibilities with polymers. $50 \mathrm{wt} \%$ of the $\mathrm{EMMBF}_{4}$ was added into the system and removed by methanol after membrane casting. The choice of solvent for membrane casting plays an important role in the manufacture of uniform pore size distribution. To lower the evaporation speed and avoid the split phase, NMP was used in the work. Figure 2 shows the field emission scanning electron microscopy (FESEM) images of the porous absorbents. The morphological structure exhibited uniform pore size distribution with an average diameter of $0.32 \mu \mathrm{m}$.

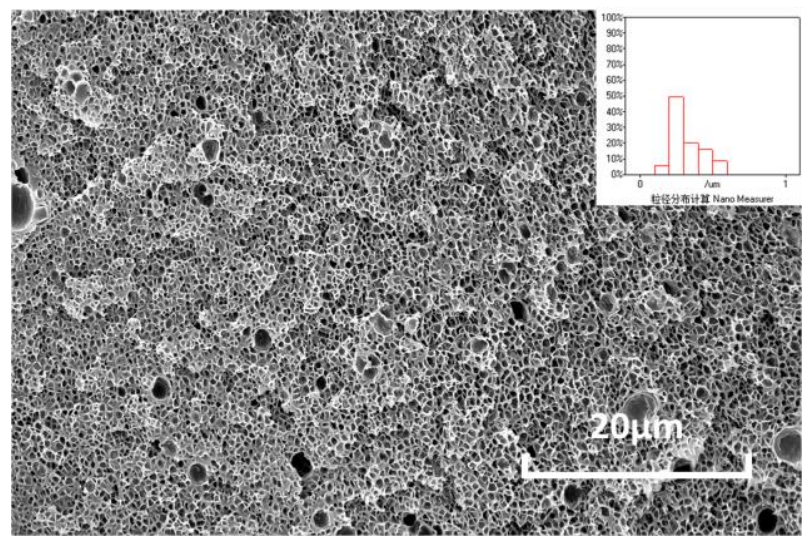

Figure 2. The SEM images of the porous IER.

$B$.

Water uptake

Water uptake at various temperatures could reveal the highest water capacity of the absorbents. As expected, both the porous and non-porous absorbents exhibited improved water uptake along with the increasing of temperature. Besides, as we can see in Fig. 3, the porous absorbents outperformed that of non-porous absorbents over the entire range of temperatures. The porous absorbent have a higher water uptake ratio of 5.9 wt\% than the non-porous particles (5.6 wt\%) after 10mins immersed into water at $20^{\circ} \mathrm{C}$, (ih)dicating 2 the enhancement of the porous surfaces on water uptake.

\footnotetext{
Identify applicable sponsor/s here. (sponsors)
} 


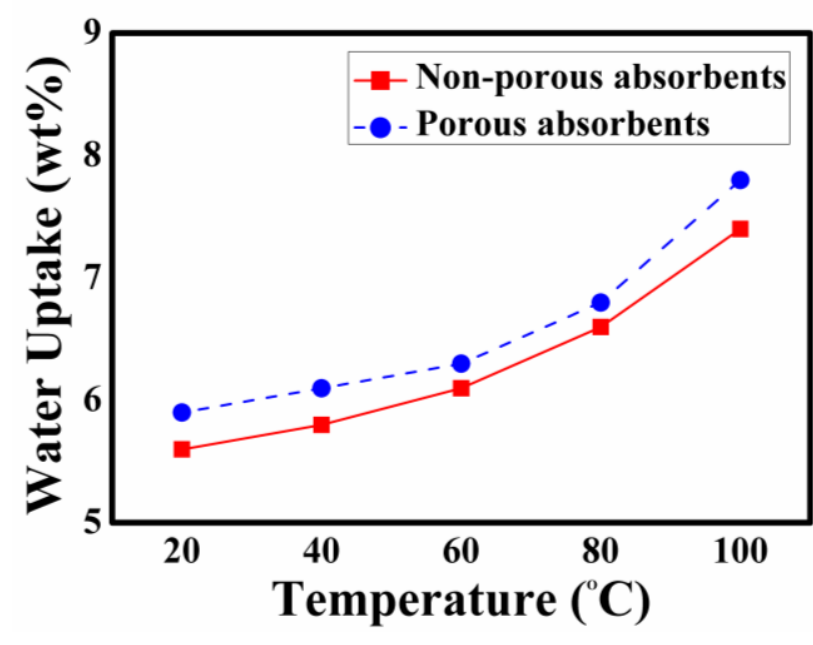

Figure 3. Water uptake of both porous and non-porous absorbents.

C.

Adsorption

$\mathrm{KCl}$ salt bath was placed in a cube to create constant $\mathrm{RH}$ atmosphere. The RH was continuously measured until constant for $5 \mathrm{mins}(68.7 \% \mathrm{RH})$. Then the dried porous and non-porous absorbents were both placed in the oven and the weight change was recorded for comparison. Both samples exhibited high adsorption rate at first and slowed down after 300s. The porous absorbents showed higher adsorption rate than that of nonporous samples. As shown in figure 4, the porous absorbents also had higher adsorption ratio $(6.3 \mathrm{wt} \%)$ after fully absorbed.

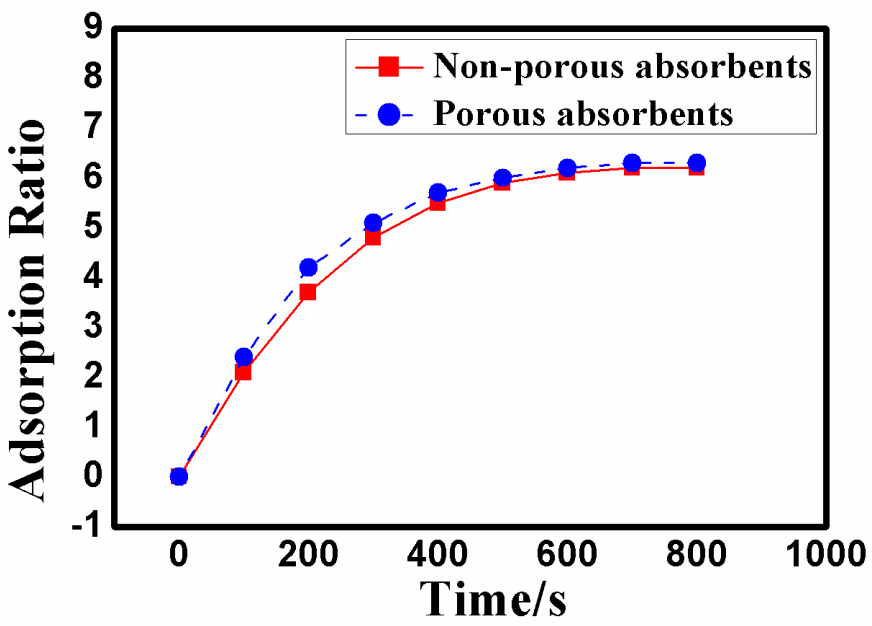

Figure 4. The adsorption ratio of both porous and nonporous absorbents.

\section{CONCLUSION}

The sulphonated poly ether sulfone ion exchange resin was successfully synthesized. To improve the adsorption capacity, the IER was fabricated with porous structure to increase the contact area with the moist air. Water uptake and adsorption ratio are investigated and compared with the non-porous absorbents. It turns out the porous absorbents exhibit both higher humidity adsorption rate and capacity due to the morphological changes. This works may provide a new method for developing high-performance desiccant coated heat exchangers.

\section{ACKNOWLEDGMENT}

We would like to thank the supporting of Hisense Air Conditioner R\&D Centre on this work.

\section{REFERENCES}

[1] MANDEGARI M A, PAHLAVANZADEH H. Introduction of a new definition for effectiveness of desiccant wheels [J]. Energy, 2009, pp. 797-803.

[2] M Tokarev, L Gordeeva, V Romannikov. New composite sorbent $\mathrm{CaCl} 2$ in mesopores for sorption cooling/heating. J. Therm. Sci., 2002, pp. 470474.

[3] N Subramanyam, MP Maiya, SS Murthy. Application of desiccant wheel to control humidity in air-conditioning systems [J]. Appl. Therm. Eng., 2004, pp. 2777-2788.

[4] I Glaznev, I Ponomarenko, S Kirik, Y Aristov Composites CaCl2/SBA-15 for adsorptive transformationof low temperature heat: pore size effect. Int. J. Refrigeration , 2011, pp. 1244-1250.

[5] Ponomarenko, I., Glaznev, I., Gubar, A., Aristov, Y.I., Kirik, S. Synthesis and water sorption properties of a new composite " $\mathrm{CaCl} 2$ confined into SBA-15 pores". Microporous and Mesoporous Material. 2010, pp. 243250 .

[6] L Gordeeva, YI Aristov. Composites salt inside porous matrix' for adsorption heat transformation: a current state-ofthe-art and new trends. Int. J. Low-Carbon Tech. 2012, pp. 288-02.

[7] TS Ge, YJ Dai, Y Li, RZ Wang. Simulation investigation on solar powered desiccant coated heat exchanger cooling system. Appl. Energ. 2012, pp. 532-540.

[8] TS Ge, YJ Dai, Y Li, RZ Wang, ZZ Peng, Experimental comparison and analysis on silica gel and polymer coated fintube heat exchangers. Energy, 2010, pp. 2893-2900.

[9] Collier Jr., R.K. Desiccant properties and their effect on cooling system performance. ASHRAE Transactions 1989, pp. 823-827.

[10] STABAT P, MARCHIO D. Heat-and-mass transfers modelled for rotary desiccant dehumidifiers [J]. Appl. Energ., 2008, pp. 128-142.

[11] X. Zheng, T.S. Ge, Y. Jiang, R.Z. Wang. Experimental study on silica gel-LiCl composite desiccants for desiccant coated heat exchanger, Int. J. Refrigeration, 2015, pp. $24-32$.

[12] A Frazzica, G Füldner, A Sapienza, A Freni, L Schnabel. Experimental and theoretical analysis of the kinetic performance of an adsorbent coating composition for use in adsorption chillers and heat pumps, Appl. Therm. Eng., 2014, pp. 1022-1031.

[13] FT. Ishugah, RZ Wang, LW Wang, ZS Lu, Performance improvement of an adsorption chiller using composite adsorbent, silica gel impregnated with lithium chloride, paired with methanol as the adsorbate, Int. J. AirConditioning and Refrigeration, 2014, pp. 1440003-1440017.

[14] ZS Lu, RZ Wang, ZZ Xia, LX Gong. Experimental and theoretical analysis of the kinetic performance of an adsorbent coating composition for use in adsorption chillers and heat pumps. Appl. Therm. Eng., 2014, pp. 1022-1031.

[15] A Freni, G Maggio, F Cipitì, YI Aristov, Simulation of water sorption dynamics in adsorption chillers: One, two and four layers of loose silica grains, Appl. Therm. Eng., 2012, pp. 69-77.

[16] H Demir, M mobedi, S Ulku. The use of metal piece additives to enhance heat transfer rate through an unconsolidated adsorbent bed, Int. J. Refrigeration, 2010, pp. 714-720.

[17] $\mathrm{CH} \mathrm{Wu}, \mathrm{SH} \mathrm{Hsu}, \mathrm{RQ} \mathrm{Chu}, \mathrm{R}$ Q Chu, MT Chen, TW Chung. Enhancing the Thermal Conductivity of the Heat Exchanger in a Noncompressive 
System as a Means of Energy Efficiency Improvement of the System, Int. J. Green Energy, 2009, pp. 490-507

[18] LW Wang, SJ Metcalf, RE Critoph, R Thorpe, Z Tamainot-Telto, Thermal conductivity and permeability of consolidated expanded natural graphite treated with sulphuric acid, Carbon, 2011, pp. 4812-4819;

[19] ZM Khazimov, GC Bora, KM Khazimov, MZ Khazimov. J. Eng. Thermophysics, 2014, pp. 306-315.
[20] MA MANDEGARI, H PAHLAVANZADEH. Introduction of a new definition for effectiveness of desiccant wheels [J]. Energy, 2009, pp. 797-803.

[21] B. Liu, Y. Dai, G.P. Robertson, M.D. Guiver, W. Hu, Z. Jiang, A comparative structure-property study of methylphenylated and fluoromethylphenylated poly(aryl ethers) and their gas permeabilities and permselectivities, Polymer, 2005, pp. 11279-11287. 